Supporting Information

\title{
Promoting Reversible Cathode Reactions in Magnesium Rechargeable Batteries Using Metastable Cubic $\mathrm{MgMn}_{2} \mathrm{O}_{4}$ Spinel Nanoparticles
}

Hiroaki Kobayashi, ${ }^{* a}$ Kouta Samukawa, ${ }^{a}$ Masanobu Nakayama, ${ }^{b}$ Toshihiko Mandai, ${ }^{c}$ and Itaru Honma $^{a}$

${ }^{a}$ Institute of Multidisciplinary Research for Advanced Materials, Tohoku University, 2-1-1 Katahira, Aoba-ku, Sendai, Miyagi, 980-8577, Japan.

${ }^{b}$ Department of Advanced Ceramics, Nagoya Institute of Technology, Gokiso, Showa, Nagoya, Aichi, 466-8555, Japan.

${ }^{c}$ Center for Green Research on Energy and Environmental Materials, National Institute for Materials Science (NIMS), 1-1 Namiki, Tsukuba, Ibaraki 305-0044, Japan.

*Corresponding author

Email: h.kobayashi@tohoku.ac.jp

Table of contents

1. Additional data for theoretical calculation: Table S1, S2, Figure S1.

2. Additional data for material characterization: Table S3-S6, Figure S3-S6

3. Additional data for electrochemical performance: Figure S2, S7-S9 
Table S1. Comparison of calculated spinel structure parameters for tetragonal and cubic MMO.

\begin{tabular}{llllll}
\hline Phase & $\begin{array}{l}\text { Space } \\
\text { group }\end{array}$ & $\begin{array}{l}\text { Lattice } \\
\text { parameters }[\AA]\end{array}$ & Atom & Site & $\begin{array}{l}\text { Atomic } \\
\text { coordination }\end{array}$ \\
\hline Tetragonal- & I4 $4_{1} /$ amd & $a=5.76081$ & $\mathrm{Mg}$ & $4 a$ & \\
$\mathrm{MgMn}_{2} \mathrm{O}_{4}$ & & $c=9.24003$ & $\mathrm{Mn}$ & $8 d$ & \\
& & & $\mathrm{O}$ & $16 h$ & $y=0.52340$ \\
& & & & & $z=0.24492$ \\
\hline **Cubic- & $F d \overline{3} m$ & $a=8.48927$ & $\mathrm{Mg}$ & $8 b$ & \\
$\mathrm{MgMn}_{2} \mathrm{O}_{4}$ & & & $\mathrm{Mn}$ & $16 c$ & \\
& & & $\mathrm{O}$ & $32 e$ & $x=0.23930$ \\
& & & & &
\end{tabular}

Table S2. Calculated migration energy, $E_{m}$, estimated diffusion coefficients, $D$, at $298 \mathrm{~K}$ and diffusion distances, $L$, by DFT-NEB results for the temperature range from $273 \mathrm{~K}$ to $323 \mathrm{~K}$ for cubic and tetrahedral MMO.

\begin{tabular}{lll}
\hline Structure & Tetragonal MMO & Cubic MMO \\
\hline$E_{m} / \mathrm{eV}$ & 0.62 & 0.67 \\
$D / \mathrm{cm}^{2} \mathrm{~s}^{-1}(298 \mathrm{~K})$ & $4.5 \times 10^{-14}$ & $6.4 \times 10^{-15}$ \\
$L(273 \mathrm{~K}) / \mathrm{nm}(1 \mathrm{~h})$ & 100 & 40 \\
$L(298 \mathrm{~K}) / \mathrm{nm}(1 \mathrm{~h})$ & 310 & 120 \\
$L(323 \mathrm{~K}) / \mathrm{nm}(1 \mathrm{~h})$ & 790 & 320 \\
\hline
\end{tabular}

Table S3. Result of CHN elemental analysis of the cubic MMO.

\begin{tabular}{llll}
\hline & $\mathrm{C}[\mathrm{wt} \%]$ & $\mathrm{H}[\mathrm{wt} \%]$ & $\mathrm{N}[\mathrm{wt} \%]$ \\
\hline Before annealing & 34.82 & 5.98 & 0.52 \\
After annealing & 0.57 & 1.05 & 0.94 \\
\hline
\end{tabular}


Table S4. Results of Rietveld refinement of the cubic MMO. ${ }^{a}$

\begin{tabular}{llllll}
\hline Phase & Space group & Lattice parameters $[\AA]$ & Atom & Site & $\begin{array}{l}\text { Occupancy }(g) \text { and } \\
\text { atomic coordination }\end{array}$ \\
\hline Cubic- & $F d \overline{3} m$ & $a=8.319(9)$ & $\mathrm{Mg}$ & $8 b$ & $g=0.965(15)$ \\
$\mathrm{MgMn}_{2} \mathrm{O}_{4}$ & & & $\mathrm{Mn}$ & $16 c$ & \\
& & & $\mathrm{O}$ & $32 e$ & $x=0.2356(6)$
\end{tabular}

${ }^{a}$ Partial profile relaxation was applied to the 440 reflection peak. $R_{\mathrm{wp}}=3.72 \%, R_{\mathrm{p}}=2.92 \%, R_{\mathrm{e}}=$ $1.88 \%, S=1.98$.

Table S5. Results of Rietveld refinement of the tetragonal MMO. ${ }^{a}$

Phase $\quad$ Space group Lattice parameters $[\AA]$ Atom Site Occupancy $(g)$ and atomic coordination

\begin{tabular}{|c|c|c|c|c|c|}
\hline Tetragonal- & I4 $4_{1} /$ amd & $a=5.7772(12)$ & $\mathrm{Mg}$ & $4 a$ & $g=0.334(2)$ \\
\hline \multirow[t]{4}{*}{$\mathrm{MgMn}_{2} \mathrm{O}_{4}$} & & $c=9.3523(19)$ & $\mathrm{Mg}$ & $8 d$ & $g=0.248(2)$ \\
\hline & & & $\mathrm{Mn}$ & $4 a$ & $g=0.666(2)$ \\
\hline & & & $\mathrm{Mn}$ & $8 d$ & $g=0.752(2)$ \\
\hline & & & $\mathrm{O}$ & $16 h$ & $x=0.2576(13)$ \\
\hline
\end{tabular}

Table S6. Results of Rietveld refinement of the cubic MMO after discharge. ${ }^{a}$

\begin{tabular}{llllll}
\hline Phase & Space group & Lattice parameters $[\AA]$ & Atom & Site & $\begin{array}{l}\text { Occupancy }(g) \text { and } \\
\text { atomic coordination }\end{array}$ \\
\hline Cubic- & $F d \overline{3} m$ & $a=8.423(18)$ & $\mathrm{Mg}$ & $8 b$ & $g=1^{b}$ \\
$\mathrm{MgMn}_{2} \mathrm{O}_{4}$ & & & $\mathrm{Mg}$ & $16 d$ & $g=0.167^{b}$ \\
& & & $\mathrm{Mn}$ & $16 c$ & $g=1^{b}$ \\
& & $\mathrm{O}$ & $32 e$ & $x=0.2576(13)$
\end{tabular}

${ }^{a} \overline{\text { Partial profile relaxation was applied to the } 444 \text { reflection peak. } R_{\mathrm{wp}}=2.70 \%, R_{\mathrm{p}}=2.07 \%, R_{\mathrm{e}}}=$ $1.36 \%, S=1.99 .{ }^{b}$ Fixed. 
(a)



(b)

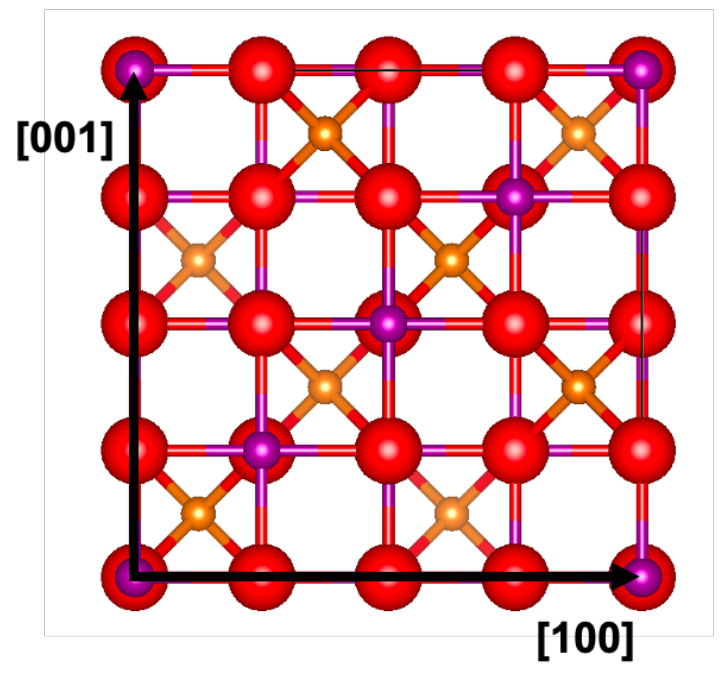

Figure S1. Crystal structures of (a) tetragonal and (b) cubic MMO. Orange, purple, and red spheres represent $\mathrm{Mg}, \mathrm{Mn}$, and $\mathrm{O}$, respectively.



Figure S2. Voltage curves of cubic MMO before annealing. A coin-type half-cell with an activated carbon anode, a $0.5 \mathrm{M} \mathrm{Mg}\left(\mathrm{ClO}_{4}\right)_{2} / \mathrm{CH}_{3} \mathrm{CN}$ electrolyte, a glass fiber separator was used. 



Figure S3. FT-IR spectra of cubic MMO (a) before and (b) after annealing.



Figure S4. A TG curve of cubic MMO. 


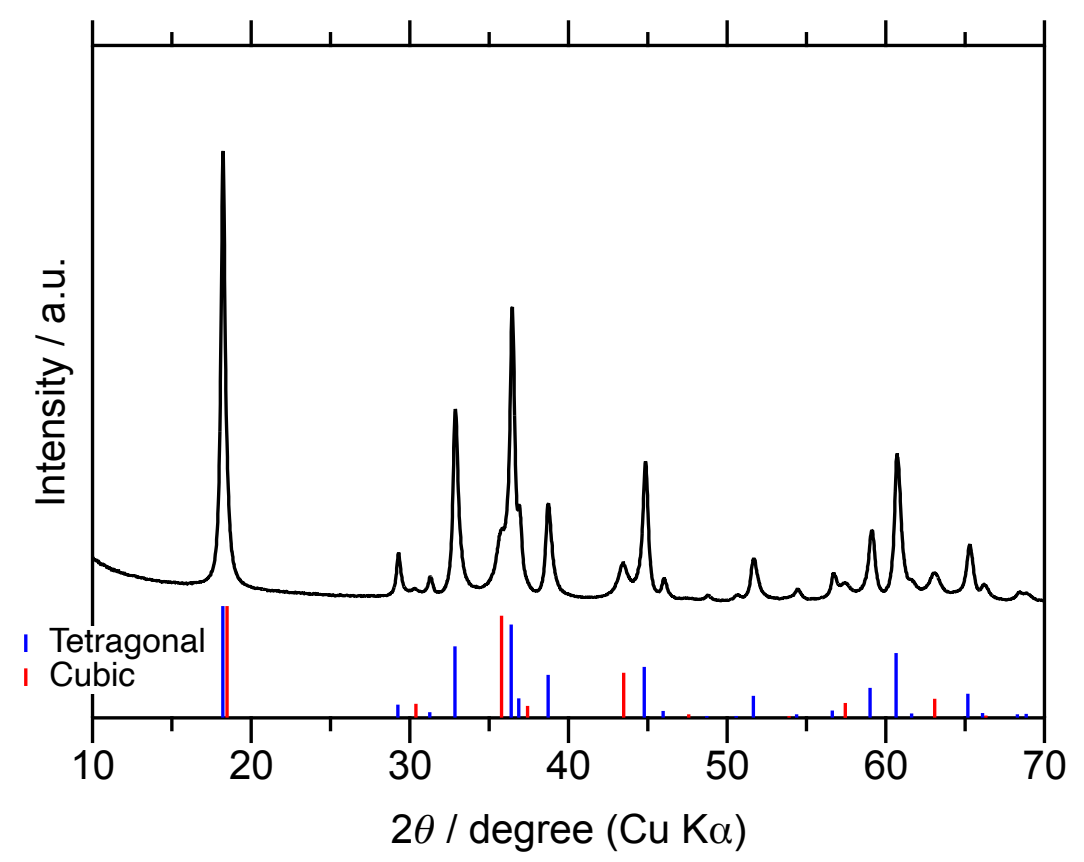

Figure S5. A XRD pattern MMO after annealing at $600{ }^{\circ} \mathrm{C}$.
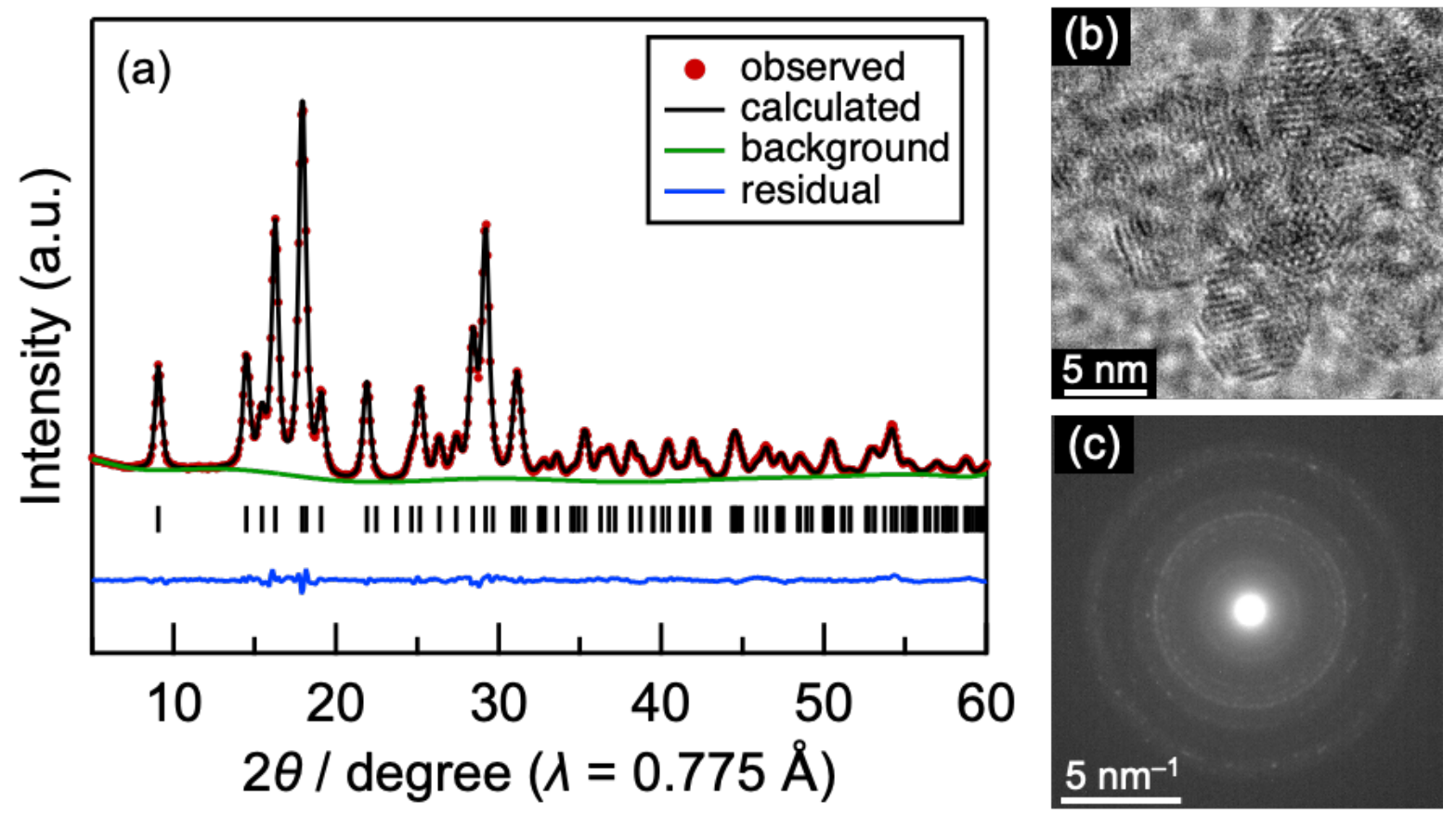

Figure S6. (a) A XRD pattern of tetragonal MMO with the fitting curve. (b) A HR-TEM image of tetragonal MMO nanoparticles. (c) SAD obtained from TEM images. 




Figure $\mathrm{S} 7 . \mathrm{d} Q / \mathrm{d} V$ plots in the half-cell test (Figure $4 \mathrm{a}$ ).
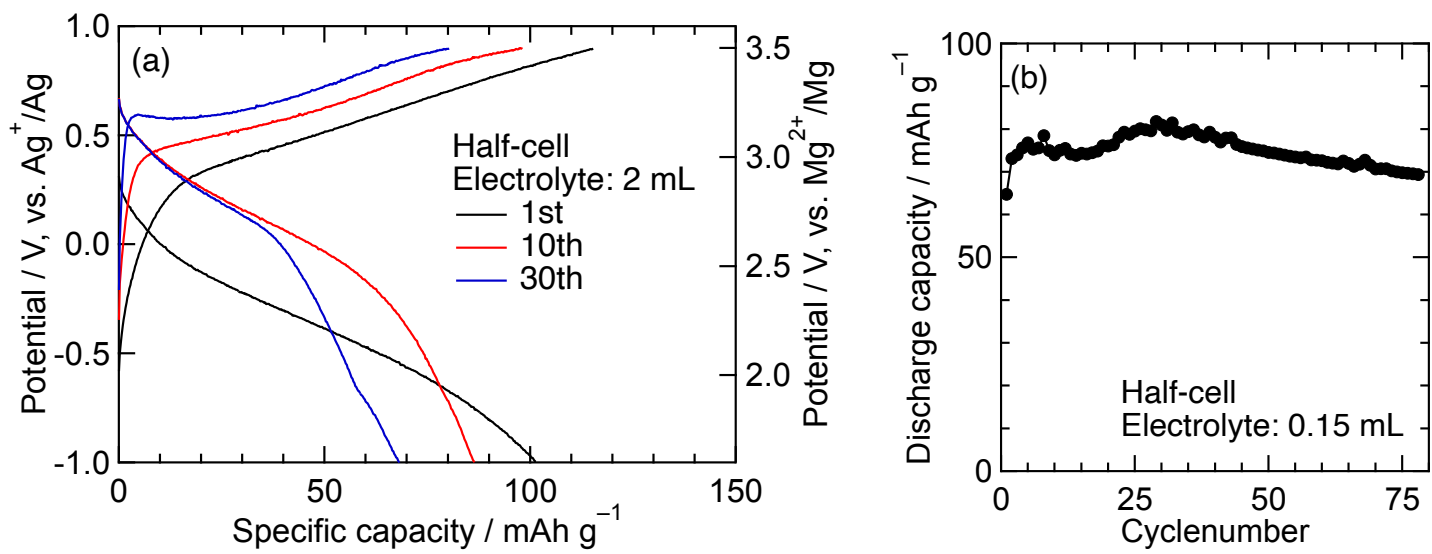

Figure S8. Cycle performance of the cubic MMO with the half-cell test.
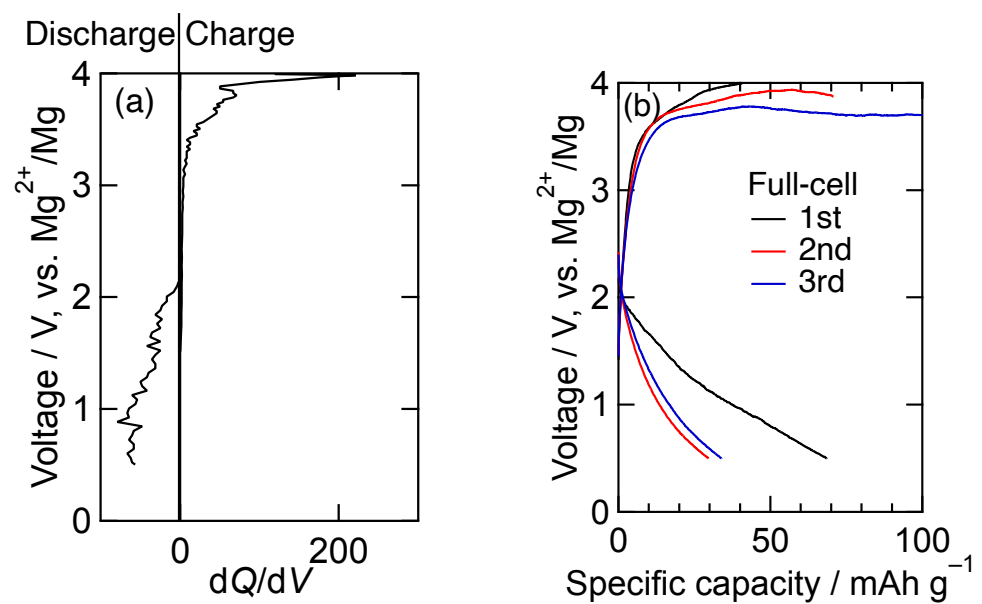

Figure S9. (a) $\mathrm{d} Q / \mathrm{d} V$ plots of the cubic MMO in the full-cell test (Figure $4 \mathrm{~d}$ ). (b) Cycle performance of the cubic MMO with the full-cell test. 